\title{
Droplet degeneration of the cornea in North Cameroon Prevalence and clinical appearances
}

\author{
JOHN ANDERSON AND HARALD FUGLSANG \\ Medical Research Council Grantholders, PO Box 55, Kumba, \\ SW Province, United Cameroon Republic
}

A corneal degeneration characterized by the presence of superficial hyaline deposits, which clinically resemble oil droplets, has been described under many different terms (Freedman, r973a; Fraunfelder and Hanna, 1973). It has been reported from many areas, including Canada (Freedman, 1965; Wyatt, 1973; Young and Finlay, 1975), the USA (Fraunfelder, Hanna, and Parker, I972; Fraunfelder and Hanna, 1973), Europe (Young and Finlay, 1975), Australia (Freedman, 1973a), South Africa (Etzine and Kaufmann, 1964; Freedman, 1973a), and SW Africa (Freedman, 1973b). Particularly severe changes have been described in Somalia (Bartolucci, 1933; Falcone, 1954; Frétillère, Védy, and Chovet, 1967), Eritrea and Saudi Arabia (Bietti, Guerra, and Ferraris de Gaspare, 1955), Red Sea islands (Zanettin, 1937; Rodger, 1973), North Africa (Gandolfi, 1962), and Iran (Barrie Jones, personal communication). Most of these studies have been of selected cases, and the prevalence of the condition in a population is unknown.

The prevalence of droplet degeneration in $5 \mathrm{I} 7$ persons aged ro years and more among defined populations in five villages in the Sudan-savanna belt of north Cameroon is reported in this paper. The clinical appearances are described and compared with those reported elsewhere.

\section{Materials and methods}

The five villages were situated on the plain stretching eastwards from Nigeria towards Chad, on both sides of the N'gaoundéré-Garoua road, at a latitude of about $8^{\circ} \mathrm{N}$. The main occupation of villagers of both sexes was subsistence farming, which involved long periods outdoors. The women were not veiled. In addition, the men engaged in hunting and fishing. The climate of north Cameroon is typical of the Sudansavanna belt of West Africa. There is a dry season which lasts about eight months, during which the day temperature reaches very high levels, and a shorter wet

This study was supported by the Medical Research Council

Address for reprints: 54 Hornton Street, London W8 $4 \mathrm{NT}$ season of intermittent heavy storms. Throughout much of the year the sky is clear, although in January and February there is often dust in the atmosphere blown down from the Sahara. Very high wind gusts can occur in the dry season, producing rotating columns of dust and sand.

The villages (Gorheck, Koumban, Lingerba, Naari, and Ndiki) were all included in an onchocerciasis survey in $1971-72$ (Anderson, Fuglsang, Hamilton, and Marshall, 1974), during which the total populations aged five years and over were examined. The present paper is concerned with a re-examination made in January-February 1975, when all persons aged Io years and over from the original population were studied.

Ocular examination was carried out in a darkened hut, using a Haag-Streit 900 slit lamp. Vision was tested using an illiterate E-chart, and blindness was defined as 'the inability to count fingers accurately at $3 \mathrm{~m}$ with the better eye'. The findings for each patient were recorded on individual record charts and sketches were made of the corneal changes.

\section{Results}

\section{PREVALENCE}

The prevalence and pattern of corneal droplet degeneration were similar in all the villages, and the results are therefore combined. Table I shows

Table I Prevalence of droplet degeneration of the cornea, by age and sex

\begin{tabular}{|c|c|c|c|c|c|c|}
\hline \multirow[b]{2}{*}{ Age } & \multicolumn{2}{|c|}{ Males } & \multicolumn{2}{|c|}{ Females } & \multicolumn{2}{|c|}{ Total } \\
\hline & $\begin{array}{l}\text { No. } \\
\text { seen }\end{array}$ & $\begin{array}{l}\text { Preva- } \\
\text { lence } \\
\text { (per cent) }\end{array}$ & $\begin{array}{l}\text { No. } \\
\text { seen }\end{array}$ & $\begin{array}{l}\text { Preva- } \\
\text { lence } \\
\text { (per cent) }\end{array}$ & $\begin{array}{l}\text { No. } \\
\text { seen }\end{array}$ & $\begin{array}{l}\text { Preva- } \\
\text { lence } \\
\text { (per cent) }\end{array}$ \\
\hline $10-19$ & 76 & 0 & 64 & 0 & 140 & 0 \\
\hline $20-29$ & 61 & $3 \cdot 3$ & 84 & $\mathrm{I} \cdot 2$ & 145 & $2 \cdot I$ \\
\hline $30-39$ & 46 & $21 \cdot 7$ & 48 & $12 \cdot 5$ & 94 & $17 \cdot 0$ \\
\hline $40-49$ & 34 & $44 \cdot I$ & 33 & $36 \cdot 4$ & 67 & 40.3 \\
\hline$>50$ & 46 & $65 \cdot 2$ & 25 & $52 \cdot 0$ & 71 & 60.6 \\
\hline Total & 263 & $21 \cdot 7$ & 254 & $12 \cdot 6$ & $5^{17}$ & $17 \cdot 2$ \\
\hline
\end{tabular}


the age and sex distribution of the population examined together with the prevalence of droplet degeneration (all degrees). Corneal changes of other aetiology, mainly onchocerciasis, prevented an assessment of droplet degeneration in 23 persons, I5 males and eight females, but these cases were not excluded from the analysis. The condition was not found in those aged under 20 years, but thereafter in both sexes there was a steady increase with age. The prevalence was greater in men than women at all ages, but the difference was smaller in the older age groups. More than 50 per cent of men and women aged 50 years and over showed the condition.

\section{CLINICAL APPEARANCES}

The clinical appearances among the 89 cases were varied, but in general the changes in any individual were similar in the two eyes. It was possible to separate the changes into mild and severe.

\section{Mild}

The mildest change consisted of an exceedingly fine granularity or stippling in Bowman's zone, visible only by retroillumination. It was as if the portion of cornea was very slightly steamed up, like breath on cold glass (Fig. I). This change was present in 78 cases ( 88 per cent), and was the only detectable one in 20 cases. Colourless 'droplets', of a size usually less than $0.1 \mathrm{~mm}$ and again only visible by retroillumination, were seen in 69 patients ( 78 per cent), and were the only recorded change in I I of them. Mild granularity and droplets were present together in 58 cases $(65$ per cent) (Fig. I). One or more regular, and usually circular or oval, clear spaces (lacunae) were present in the granular or stippled areas in 16 patients (Fig. I). They seldom exceeded $\mathrm{I} \mathrm{mm}$ in diameter and were usually considerably smaller.

These mild changes alone were present in 80 patients ( 90 per cent), and they were bilateral in 56 of them (70 per cent). They were confined to the peripheral $1 \frac{1}{2}-2 \mathrm{~mm}$ of cornea in 77 cases, with the following distribution:

\begin{tabular}{|c|c|c|}
\hline \multirow{4}{*}{$\begin{array}{l}\text { Temporal alone } \\
\text { Nasal alone } \\
\text { Temporal and nasal }\end{array}$} & Cases & Percentage \\
\hline & 30 & 39 \\
\hline & I0 & 13 \\
\hline & 37 & 48 \\
\hline & 77 & 100 \\
\hline
\end{tabular}

Thus the temporal cornea was affected in a total of 67 cases ( 87 per cent), and the nasal in 47 (6I per cent). In two patients mild changes were also present in the intermediate corneal zone (Fig. 4), and in one the central area was involved (Fig. 3). None of these lesions stained with fluorescein.

In about half the cases described above there was an area of clear cornea of variable extent between the lesion and the limbus. The corneal edge of these clear areas was sometimes highly contoured (Fig. I), as described by Freedman (i965). In a few eyes the clear periphery was connected to a lacuna within the lesion, and occasionally the lesion was bisected by clear cornea (Fig. 2). In the rest the lesions seemed to extend right up to the limbus.

Central vision was reduced in Io persons with mild lesions, but in only one of them, who showed central corneal changes, could droplet degeneration be implicated. He was a man of about 70 years, in whom bilateral cataracts were mainly responsible for the reduction of vision to counting fingers at I $\mathrm{m}$ with one eye and at $3 \mathrm{~m}$ with the other. The main cause of reduced vision in the other nine patients was iritis (I), cataract (5), dislocation of the lens (I), and optic atrophy (2).

\section{Severe}

Only nine patients showed changes other than granularity and formation of small droplets. They were not a uniform group, although all showed areas of granularity and/or droplets and all but one showed changes in both eyes. These are summarized in Table II, which shows that only one was a female and that most of them were aged 60 years or more. The two cases in which large protruding yellow nodules were visible were both elderly men with soft degenerating eyes. Fig. 5 represents the left cornea of the 84-year-old man, whose right cornea is shown in Fig. 4.

\section{OTHER CONDITIONS}

The prevalence of onchocerciasis in persons aged five years and over ranged from 85 to 94 per cent in the villages studied (Anderson and others, 1974). Among the 89 cases with droplet degeneration microfilariae of Onchocerca volvulus were seen in the cornea in 39 ( 44 per cent) and in the anterior chamber in 34 ( 38 per cent).

Pterygia were present in 16 out of the 232 villagers aged 30 years and over ( 7 per cent), and the prevalence was the same in cases with or without droplet degeneration.

\section{Discussion}

Most authors (Falcone, 1954; Bietti and others, 1955; Freedman, 1965; Frétillère and others, 1967; Wyatt, 1973) have emphasized the prepon- 
Table II Age, sex, visual acuity, corneal involvement, and other associated ocular lesions in nine cases with severe corneal changes

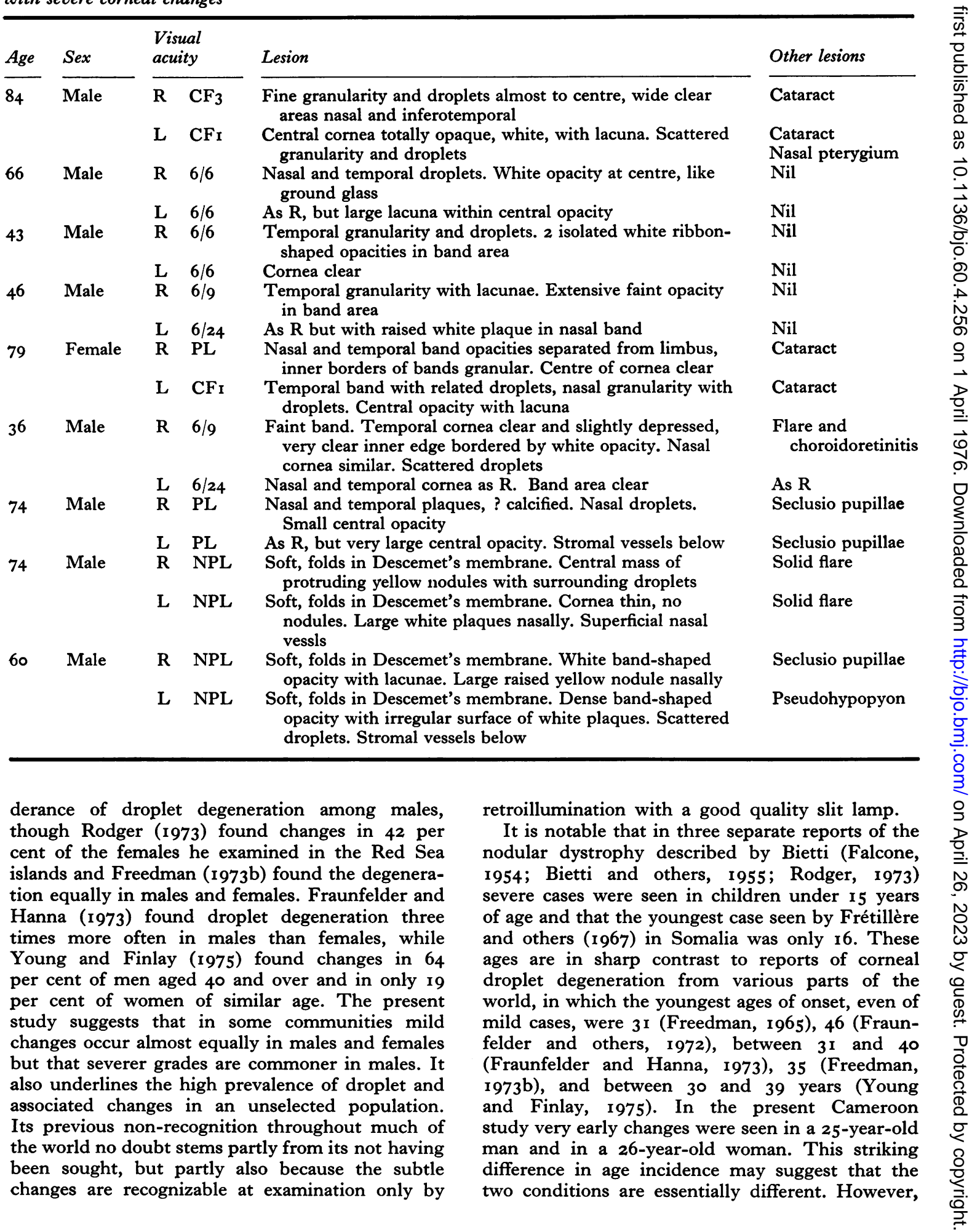




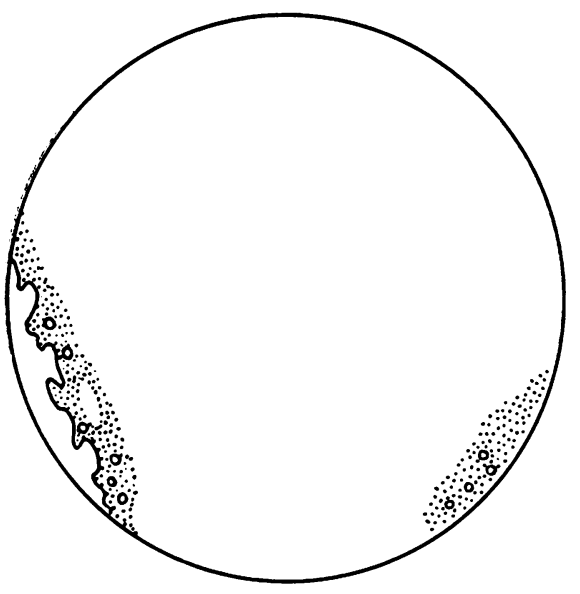

FIG 1

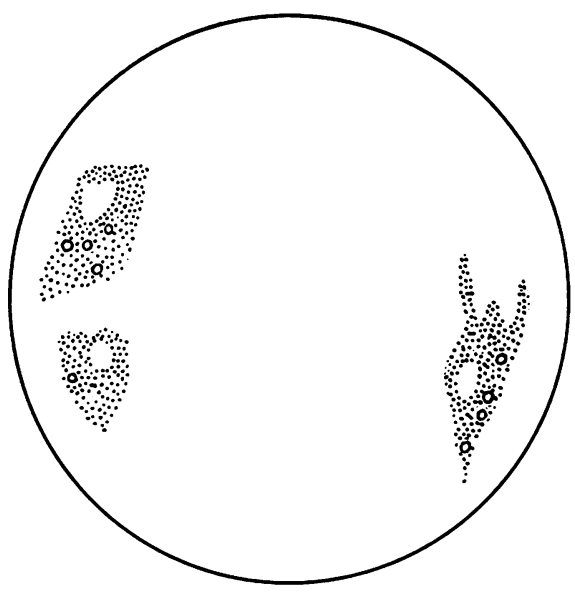

FIC 2

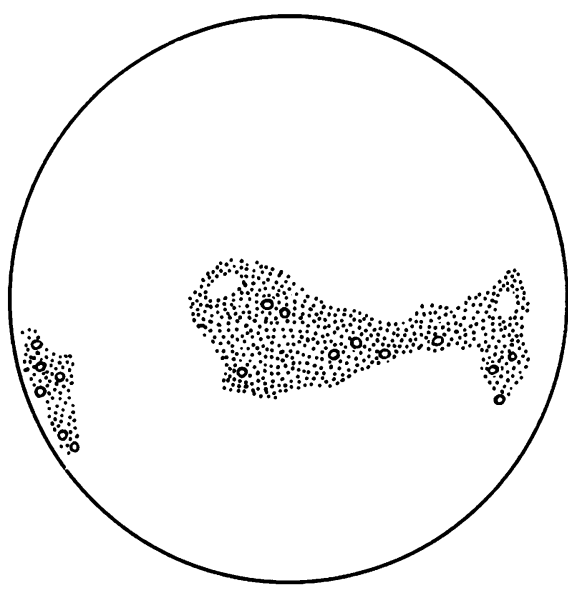

FIG 3

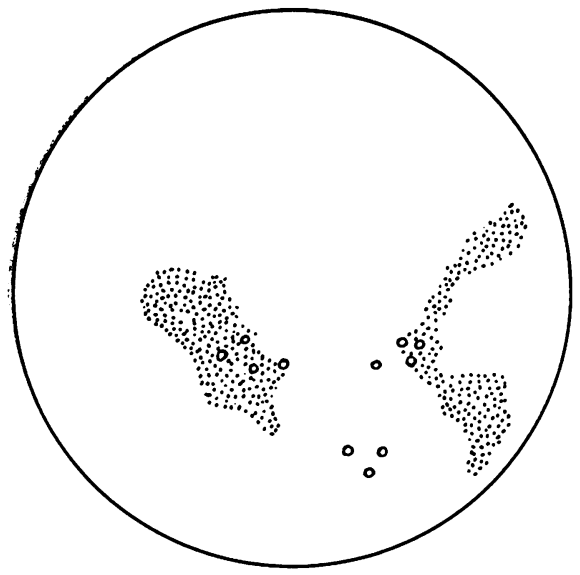

FIC 4

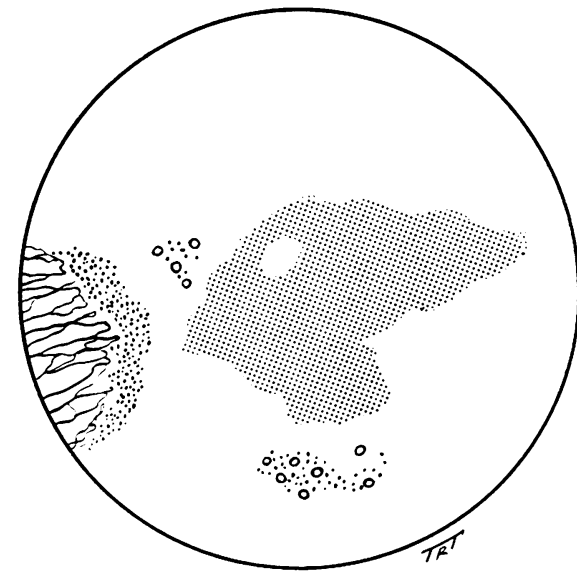

FIG 5

FIGS I-5 Different degrees of droplet degeneration ranging from very mild peripheral (Figs $\mathrm{I}$ and 2 ) to more severe central changes (Fig. 5). Areas of granularity with scattered droplets in all lesions, with dense central opacity as well as a pterygium in one (Fig. 5) 
the histopathology of the lesions is the same in both (Freedman, 1973a; Garner, Morgan, and Tripathi, 1973), and possibly aetiological factors such as climate, nutritional status, occupation, and coexisting ocular disease govern the age of onset and subsequent clinical picture.

The finding of bilateral changes in 65 out of the 89 cases ( 73 per cent) is in agreement with most previous workers (Bietti and others, 1955; Freedman, 1965), but the secondary corneal type of Fraunfelder and Hanna (1973) was more often unilateral. In the series of 144 cases reported by Frétillère and others (1967) rather more than half were unilateral. Falcone (1954) emphasized that the lesions in Somalia nearly always appeared first on the temporal side of the cornea, and he included this as a factor in support of the aetiological role of sunlight in their development. In Labrador, however, Freedman (1965) implied that the nasal limbus was involved as often as the temporal, and his findings were supported by those of Fraunfelder and others (1972), Freedman (1973b), and Young and Finlay (1975). The present study also supports the findings of these last workers.

Droplet, or spheroidal, keratopathy or degeneration has been differently graded and classified by different workers. Freedman (1965, 1973a) distinguished peripheral from central involvement, and further subdivided the latter according to visual standard. Fraunfelder and others (1972) and Fraunfelder and Hanna (1973) distinguished between corneal and conjunctival degeneration, and subdivided the former into primary and secondary. The primary degeneration was located only in the periphery of the cornea, while the secondary was always, or almost always, associated with other ocular and, more specifically, corneal lesions. In the present study the finding that changes in the intermediate and central corneal zones were identical and continuous with the early peripheral changes, even in eyes without other corneal lesions, suggests that a classification confining primary degeneration to the corneal periphery is unsatisfactory. Seemingly a classification based on visual acuity will also be unsatisfactory because of the possible reduction of acuity by causes other than droplet degeneration. In the present study, for example, nine or to cases out of 80 with mild droplet degeneration had reduced visual acuity from other causes (mainly onchocerciasis). For these reasons it might be better to refer to the changes as mild when only granularity and/or droplets are seen and severe when more advanced changes are present, and to specify the distribution in both cases.

Provided a good slit lamp is available and the examiner is searching for the condition there is no difficulty in diagnosing the slight and subtle changes of mild droplet degeneration of the cornea. How $\frac{0}{3}$ ever, when the cornea is more extensively damaged problems of differential diagnosis arise. It may even be impossible in certain cases, unless they have? been studied longitudinally, to arrive at a correct? diagnosis. Isolated central corneal opacities, even when in the typical band position, need not berelated to limbal areas of granularity and droplets? However, the severe central changes represented in Fig. 5 may reasonably be supposed to share the same pathogenesis as the widespread mild changesin the fellow eye (Fig. 4). Notably, not one case in $\vec{w}$ this series showed an 'uncomplicated' banof opacity such as was described and illustrated byo. Bietti and others (1955) and Freedman (1965) 8 Both cases in which frank yellow corneal nodulest were present also showed vascularization of the cornea and damage to deeper ocular structures.

The cases of mild droplet degeneration seen in the present series corresponded very closely with most of those described by Freedman (1965) ino Labrador and by the same author (1973a) in South Africa and Australia. The cases classed bye Fraunfelder and others (1972) as primary spheroidor degeneration of the cornea also seemed to correspond, although these authors described the spher ules as having various shades of yellow to gold ande they implied that the cornea between each spherulen was initially clear. They made no reference to the typical fine granularity or to the clear area between the lesion and the limbus which were seen in Labrador and Cameroon.

The descriptions of the early stages of the्ठ disease as recorded from East Africa, the Red Sea littoral, and Saudi Arabia are less easy too. follow and more difficult to correlate with our' findings. Falcone (1954) referred to Bowman's membrane as having a turbid, granular appearance, $\stackrel{0}{0}$ while Rodger (1973) used the descriptive term 'veil' for the early changes. For Bietti and others? (1955) the dystrophy was clearly distinguished $\triangle$ from classical band-shaped degeneration by the fact that it began more or less in the centre of then cornea and always at a considerable distance from the limbus. However, they did not have the ad-O vantage of a modern slit lamp, and therefore could not have seen the subtle peripheral changes. In one of their biopsy specimens they described tinyo hyaline droplets in or just deep to Bowman's membrane, and probably this would have shown as: granularity or stippling with a modern slit lamp at high magnification.

There are few reports on the natural history of $\stackrel{\circ}{?}$

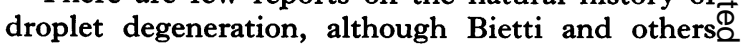
(1955) described its development based on Guerra's observations in Eritrea during eight years, ando Freedman (1965) mentioned changes in one caseo in Labrador after a year. Fraunfelder and others 
(1972) referred to a number of patients followed-up for more than three years. Most remained fairly stationary, and when they progressed there was a slow spread in a semicircular pattern adjacent to the limbus. The present paper does not attempt to describe the development of these lesions, but the changes of onchocerciasis were followed for four years and from the initial rough sketches of droplet degeneration it appears that changes had not been marked over this period.

Most authors have invoked climatic factors in the pathogenesis of droplet degeneration. In this connexion the condition was also looked for in the rain-forest zone of Cameroon during a large-scale onchocerciasis survey of over 600 patients. In the rain forest the sky is overcast for much of the year and exposure to bright sunlight is much less than in the savanna of north Cameroon. There is also less dust and sand in the rain-forest atmosphere and nothing to compare with the dust storms and desiccation that occur in the north. Interestingly, therefore, only one or two mild cases of droplet degeneration were found among the elderly in the rain-forest. The corneal changes of onchocerciasis in Cameroon were also much more pronounced in the savanna than in the rain-forest, and the more severe grades of sclerosing keratitis were confined to the savanna (Anderson and others, 1974). Thus, by analogy with our findings on droplet degeneration, it seems that climate, and especially exposure to sunlight, should also be considered as one of the many factors that may contribute to the regional differences found in ocular onchocerciasis.

Although the prevalence of onchocerciasis was high in cases of droplet degeneration it was equally high in cases without, and there was no correlation between the intensity of infection with $O$. volvulus and the prevalence and severity of droplet changes.

In his study of droplet degeneration (Labrador keratophy) Wyatt (1973) found mild changes in 28 out of 47 men aged 40 and over (6o per cent) in Labrador, while the same observer, presumably using the same examination and survey techniques, recognized it in only 21 out of 320 (7 per cent) men aged 40 and over in the Canadian north. The most severe grade was absent from the latter area, whereas it was seen in 9 of the 47 men examined in Labrador. An obvious difference between the two areas is in the amount of exposure to ultraviolet light, and more research is required on the effects of actinic radiation on the human cornea (Klintworth, 1972; Rodger, 1973).

An association between droplet degeneration and pterygium and pinguecula has often been commented on, particularly with reference to pathogenesis. In the series of Bietti and others (1955) pterygium was rare, while in Labrador signs of droplet degeneration were conspicuously absent in patients with active pterygium (Freedman, 1965). Rodger (1973) found pterygia twice as commonly in patients exhibiting Bietti's dystrophy, and Young and Finlay (1975) found an association between droplets and pinguecula and pterygium. However, they failed to explain the higher prevalence of pterygium on the nasal side compared with the equal nasal and temporal distribution of droplet degeneration. In the present study the finding that pterygium was equally common in persons with or without droplet degeneration supports the view that the two conditions, both commoner in older persons, are not otherwise related.

Globular hyaline deposits in the superficial stroma and epithelium of the cornea, which clinically resemble oil droplets, are often observed in association with other corneal disorders, such as post-traumatic scarring (Garner, 1969). The nature of their formation is still obscure (Hanna and Fraunfelder, 1972), as is their ultrastructure (Garner and others, 1973), and this has led to disagreements among clinicians and pathologists about the terminology which should be adopted (Fraunfelder and Hanna, 1973; Garner, 1969; Freedman, 1973a; Rodger, 1973). There is also difficulty in accepting under one heading all the mild and severe changes hitherto described. These difficulties will be resolved only by intensive epidemiological studies in different parts of the world.

\section{Summary}

The prevalence of droplet degeneration of the cornea in a defined population of 517 persons in north Cameroon was similar in males and females, but severe changes were commoner in elderly men. Most cases showed only mild changes of granularity and droplet formation in Bowman's zone, but they were sometimes widespread. More severe changes were seen in only nine patients. The clinical appearances are compared with those described from other parts of the world. In support of the aetiological role of direct sunlight, droplet degeneration was much more prevalent in the savanna than in the rain-forest in Cameroon.

The condition ranges in severity from very mild to very severe, but difficulties in differential diagnosis, particularly in advanced cases, make it doubtful whether the same basic condition is being described in all cases. These doubts will be resolved only by properly conducted epidemiological studies in different parts of the world.

We thank Mr A. Freedman, Dr B. O. L. Duke, and Professor G. S. Nelson for helpful criticism of the manuscript, and Mr T. R. Tarrant for the preparation of the Figures. 


\section{References}

anderson, J., fuglsang, H., hamilton, P. J. S., and Marshall, T. F. DE c. (1974) Trans. roy. Soc. trop. Med.

Hyg., 68, 209

BARTOLUCCI, F. (1933) Arch. ital. Sci. med. colon., I4, 430

BIETTI, G. B., GUERRA, P., and FERRARIS DE GASPARE, P. F. (1955) Bull. Soc. franc. Ophtal., 68, IOI

etZine, S., and kaufmann, J. c. E. (r964) Amer. F. Ophthal., 57, 760

FALCONE, c. (1954) E. Afr. med. F., 3I, 47I

FRAUNFELDER, F. T., and HANNA, c. (1973) Amer. Y. Ophthal., 76, 4I

, and PARKER, J. M. (1972) Ibid., 74, 82 I

FREEDMAN, A. (1965) Arch. Ophthal., 74, 198

(1973a) Ibid., 89, 193

FREEDMAN, J. (1973b) Brit. $\mathcal{F}$. Ophthal., 57, 688

FRÉTILLÈRE, Y., vÉDY, J., and CHOVET, M. (1967) Méd. trop., 27, 293

GANDOLFI, A. (1962) Boll. Oculist., 41, 129

GARNER, A. (1969) Brit. F. Ophthal., 54, 769

-, MORgan, G., and Tripathi, R. C. (1973) Arch. Ophthal., 89, 98

HANNA, C., and FRAUNFELDER, F. T. (1972) Amer. F. Ophthal., 74, 829

kLINTWORTH, G. K. (1972) Amer. F. Path., 67, 327

RODGER, F. C. (1973) Brit. F. Ophthal., 57, 657

WYATT, H. T. (r973) Canad. f. Ophthal., 8, 298

YOUNG, J. D. H., and FINLAY, R. D. (1975) Amer. F. Ophthal., 79, 129

ZANetTin, G. (1937) Arch. ital. Sci. med. colon., 18, 387 